\title{
Employment Effects Model Construct of Technological Progress Based on System Dynamics
}

\author{
Zhao $\mathbf{L i}^{1}$ \\ 1 School of International Education,Shandong University \\ of Finance and Economics, \\ Jinan, P.R.China
}

\author{
Zhang Hongxia ${ }^{2}$ \\ 2 School of Economics, Shandong University of \\ Finance and Economics, \\ Jinan, P.R.China
}

\author{
Wang Xuke ${ }^{3}$ \\ ${ }^{3}$ School of Business Administration,Shandong University of Finance and Economics, \\ Jinan, P.R.China
}

\begin{abstract}
Employment Effects System of Technological Progress (EESTP) is a comparatively complex system built within Society Economy System (SES). The basic function of EESTP is to integrate, negotiate and condense separated positive-direction powers, to form an enlarged co-power, and to accelerate the production of its effects on employment. Within EESTP, there are processes such as exchange, transformation, and flowing between material flow, information flow, energy flow, and talent flow among these subsystems. What's more, there is a broad communication in energy, information, material as well as talents between the effects system and regional social environment, economic environment, technological environment as well as system environment. The state and working mechanism of EESTP is a result of mutual coupling of dominating feedback loops, mainly represented as positive feedback loop involving security subsystem, operation subsystem, dynamism subsystem as well as target subsystem and negative feedback loop composed of operation subsystem, constraint subsystem, security subsystem and target subsystem.
\end{abstract}

Keywords:technological progress, employment, system dynamics

\section{Introduction}

Technological progress has promptly promoted the productivity of labor and enhanced the remarkable advance in force of production as well as economical development. However, what's the influence of technological progress upon employment? On this question, various viewpoints are achieved. De Domar model framework by Douglas Jones(1983) identified that the overall effects of technological progress was to worsen unemployment; by simulating this effect, David Deaton and Peter Nolan model (1983)indicated technological progress decreased employed population. Pissarides (1990) came up with job-creation mechanism. By using search and unemployment theory, he concluded "capital effects" on the indirect compensation to employment.By establishing a model related to unemployment and its employment increase, Aghion and Howitt (1994)made the rate of destruction endogenous and showed that unemployment would occur when the increase of productivity was obtained through high-productivity work replacing low-productivity work. Vivarellia (1995)and other scholars came up with the compensation mechanism to employment by combining the results of different compensation mechanisms as well as their valid studies by economists from Marxism, Classicalism, and Neoclassicism. Mortensen (1998) introduced the concept "Execution Cost", involving these two types of technological progresses into the overall analysis framework. Fernando del Rio(2001) mentioned that Pissarides and other scholars all assumed a compensatory relation between capital and labor. In fact, these two elements can be replaced by each other. So Pissarides believed that, assuming the rate was changeable, technological progress promoted rate thus causing a relative increase in the cost of capital and more labor was used to replace capital, which eventually reduced the rate of unemployment. Bharat trehan(2003), by a series of studies in technological progress, economy increase and employment performance since 1870s in developed countries, concluded a difference in employment performance in the US and continental European countries. He believed that the underlying reason of this difference lay not in systematic factors such as labor market but in the leading advantage of the US in technological field represented by IT, which promoted the employment.Alain de Serres (2003)found after calculation that there were some changes in the construct of America's technological progress and this progress contributed almost $60 \%$ to productivity growth since the rapid development of materialized one.

By use of the analysis framework of system dynamics, scientific system theory and system dynamics method, the 
author regards this Effects as an economy-society complex system and construct a framework model of EESTP as well as a dominant circuit model, with analysis such as casual feedback loop.

\section{Framework model construct of employment effects system of technological progress}

\subsection{Framework Construct of EESTP}

The Framework Construct of EESTP is an open and complex system with certain structure and function constructed through the interaction between different subsystems. Its meaning can be represented as EESTP $\{\mathrm{S} 1$, $\mathrm{S} 2$, . . . Sm, Ei, Ci, Fi, Rel, O, Rst, T, L $\}(\mathrm{m} \geq 2)$. In this formula, $\mathrm{Sm}$ refers to the mth subsystem, $\mathrm{Ei}, \mathrm{Ci}, \mathrm{Fi}$ refer to respectively the elements, structures and functions of each subsystem, and Rel is a system association and a correlation set within EESTP concluding relationship between subsystems as well as relationship within each subsystem, and EESTP has a relation with SES. What's more, $\mathrm{O}$ is a target system of EESTP; Rst is a restriction or constraint set. $\mathrm{T}$ and $\mathrm{L}$ represent respectively time and space variables and $\mathrm{m}$ is the number of subsystems. Research on EESTP must be related to certain SES which is a complex system through the coupling between technology, system, environment, innovation system and market. So from the point of SES, this effects system is a subsystem of SES and it comes up with how technological progress has comprehensive effects on employment and promotes the optimization and improvement.

EESTP involves a correlation between associated dimensions. It is influenced by technology and economy horizontally and by internal working of organizations and external social environment vertically. Technical level, economic level, internal working of organizations and external social environment construct the boundary of system operation. So we believe EESTP is a complex system established within SES consisted of dynamics subsystem, security subsystem, operation subsystem, constraint subsystem and target subsystem. And these five subsystems influence each other, interact with each other and interrelate with each other, constructing a system with multiple feedback functions and certain structural characteristics.

\subsection{Function and Structure Analysis of EESTP}

\subsubsection{Function Analysis of EESTP}

Firstly, most technological progress effects influenced and restricted by various socioeconomic factors are in positive direction while some are in negative direction. If these effects are carried out separately, although in positive direction, it is hard to form an integrated force, not to mention producing multiple effects. The basic function of effects system construct is to integrate, coordinate and condense the separated positive-direction forces to form an amplified joint force and then promote employment Effects of technological progress, differentiating or restricting the negative forces properly. Secondly, due to the collaboration with various departments and industries, which makes employment effects in an informal operation state, the construct system can guarantee the effects system operating in normality and durability from policy aspect, mechanism aspect and system aspect. As a result, a long-term mechanism is improved. Thirdly, the employment system integrates multiple factors such as technology, system, industry, education as well as man resources and promotes the combination of relevant factors. As a result, an organic coordination is formed between them and thus an integrated effect; what's more, the mutual promotion and organic linkage between them are promoted to exert coupling and industrial resonance effects. Fourthly, through correlation and infiltration, the relevant factors in SES are involved in EESTP. As a result, the regulation ability is strengthened, which provides a reliable support for the integration and promote indirect effects of technological progress on employment.

\subsubsection{Structure Analysis of EESTP}

EESTP includes not only elements under conditions of technological progress, but also elements of economic system and social system promoted through technological progress. That is to say, EESTP in itself is a complex technology-economy-society system, in which technological system, economic system and social system interweave each other, relate to each other to form a symbiotic relation following certain developing rules. Technological system provides a material environment for this system, including various technological factors related to technological progress such as technological upgrade, transformation and optimization; economic system provides an industrial environment for this effects system, including various factors related to technological progress within a city's primary industry, secondary industry and tertiary industry and involving various links such as scope, field, quantity and scale of employment. Social system is a combination of non-material production formed by its subject activities, including workers awareness, policy and legal system and system mechanism. Within the effects system, there are processes such as exchange, transformation, and flowing of material flow, information flow, energy flow, and talents flow between these subsystems. What's more, there is a broad communication in energy, information, material as well as talents between the effects system and regional social environment, economic environment, technological environment as well as system environment. 


\section{Leading Causal Loop Model of EESTP and Its Evolution}

\subsection{Positive Feedback Loop Composed of Security Subsystem, Operation Subsystem, Dynamics Subsystem and Target Subsystem.}

The positive feedback loop of EESTP can be divided into six categories:

A.Technology Input $\rightarrow$ Technological Innovation $\rightarrow$ Third Industry Development $\rightarrow$ Variation of Industrial $\quad$ Structure $\rightarrow$ Urbanization Development $\rightarrow$ High-tech $\quad$ Industries $\rightarrow$ Labor Employment $\rightarrow$ Enterprise Development $\rightarrow$ Technology Input

B.Technology $\quad$ Input $\rightarrow$ Technological Innovation $\rightarrow$ Third Industry Development $\rightarrow$ Raising of Income Level $\rightarrow$ Increase of Consumer Demands $\rightarrow$ Production $\quad$ Expansion $\rightarrow$ Labor Employment $\rightarrow$ Enterprise Development $\rightarrow$ Investment Input $\rightarrow$ Government Investment in Science and Technology $\rightarrow$ Technology Input

C.Technology $\quad$ Input $\rightarrow$ Technological Innovation $\rightarrow$ New $\quad$ Produce $\quad$ Development $\rightarrow$ Price Fall $\rightarrow$ Increase of Consumer Demands $\rightarrow$ Labor Employment $\rightarrow$ Production $\quad$ Expansion $\rightarrow$ Service-oriented Government $\rightarrow$ Science and Technology System $\rightarrow$ Technology Input

D.Technology

Input $\rightarrow$ Technological

Innovation $\rightarrow$ New Produce Development $\rightarrow$ New Demands Generation $\rightarrow$ Investment Input $\rightarrow$ Government Investment in Science and Technology $\rightarrow$ Technology Input

E.Technology

Innovation $\rightarrow$ High-tech Input $\rightarrow$ Government Investment in Science and Technology $\rightarrow$ Technology Input

3.2 Negative Feedback Loop Composed of Operation Subsystem, Constraint Subsystem, Security Subsystem and Target Subsystem.

The negative feedback loop of EESTP can be divided into four categories:

A. Labor Employment $\rightarrow$ Human Capital Investment $\rightarrow$ Redundancy $\rightarrow$ Production $\quad$ Mechanization $\rightarrow$ Labor Employment

$$
\text { B.Labor }
$$

Development $\rightarrow$ Capita $\rightarrow$ Technological Innovation $\rightarrow$ Production Mechanization $\rightarrow$ Labor Employment

C.Labor

Employment $\rightarrow$ Enterprise

Development $\rightarrow$ Capital $\quad$ Investment $\rightarrow \quad$ Government Investment in Science and Technology $\rightarrow$ Technology Input $\rightarrow$ Technological Fluctuation $\rightarrow$ Increase of Investment Risk $\rightarrow$ Labor
Employment

D.Labor

Employment $\rightarrow$ Enterprise

Development $\rightarrow$ Capital $\quad$ Investment $\rightarrow \quad$ Government Investment in Science and Technology $\rightarrow$ Technology Input $\rightarrow$ Technological Innovation $\rightarrow$ Labor Demand Change $\rightarrow$ Production Mechanization $\rightarrow$ Labor Employment

By analysis, one can find that the state and working mechanism of EESTP is a result of the mutual coupling of feedback loop. A study of method used by system feedback loop and the state of elements in the system together with some controlling can fulfill the object of EESTP.

\section{Conclusion}

EESTP is a complex system built within social-economy system, consisting of five subsystems, that is, dynamism subsystem, security subsystem, operation subsystem, restraint subsystem and target subsystem. These subsystems influence together, work together, related to each other, constructing a system with multiple feedback function and certain design features.

The state and working mechanism of EESTP is a result of the mutual coupling of feedback loop, representing as a regenerative loop involving security subsystem, operation subsystem, dynamism subsystem as well as target subsystem and a negative feedback loop consisted of operation subsystem, constraint subsystem, security subsystem and target subsystem.

\section{References}

[1]. Douglas Jones, "Technological Change,Demand and Employment", in Derek L, Boswortheds, The Employment Consequence of Technological Change, The Macmilland Press Ltd, 1983.

[2]. David Deaton, Peter Nolan, "The Nature of Unemployment under Technical Progress”, in Derek L, Boswortheds, The Employment Consequence of Technological Change, The Macmilland Press Ltd, 1983.

[3]. Pissarides,C.A,"Equilibrium Unemployment Theory",Basil Blackwell, London, 1990.

[4]. Ahion, P., P. Howitt, "Growth and Unemployment", Review of Economic Studies, vol.61,pp.477-494,1994.

[5]. Marco Vivarelli, "The Economics of Technology and Employment: Theory and Empirical Evidence”, Elgar, Aldershot, 1995.

[6]. Mortensen , D.T. , “ Technological Progress,Job Creation and Job Destruction” ,Review of Economic Dynamics, vol.1,pp.733-753,1998. 
[7]. Fernando del Rio, "Embodied Technical Progress and Unemployment”, Université catholique de Louvain, Institut de Recherches Economiques et Sociales IRES Discussion Paper,No.031,2001.

[8]. Bharat Trehan, "Productivity shocks and the unemployment rate”, Economic Review, Federal Reserve Bank of San Francisco, vol.1,pp. 13-37,2003.

[9]. Alain de Serres, "Structural Policies and Growth: A Non-Technical Overview", ECO Working Paper, No.355,2003. 